\title{
The effects of disturbance and enemy exclusion on performance of an invasive species, common ragweed, in its native range
}

Post-print/Accepted manuscript

A. Andrew M. MacDonald

Peter M. Kotanen

MacDonald, A.A.M. \& Kotanen, P.M. Oecologia (2010) 162: 977. doi:10.1007/s00442-009-1557-9

The final publication is available at Springer via http://dx.doi.org/10.1007/s00442-009-1557-9

\section{HOW TO CITE TSPACE ITEMS}

Always cite the published version, so the author(s) will receive recognition through services that track citation counts, e.g. Scopus. If you need to cite the page number of the TSpace version (original manuscript or accepted manuscript) because you cannot access the published version, then cite the TSpace version in addition to the published version using the permanent URI (handle) found on the record page. 
118 December 2009

2 The effects of disturbance and enemy exclusion on performance of

3 an invasive species, common ragweed, in its native range

4

5 A. Andrew M. MacDonald ${ }^{1}$ and Peter M. Kotanen ${ }^{2 *}$

6 Department of Ecology and Evolutionary Biology

7 University of Toronto Mississauga

83359 Mississauga Road N

9 Mississauga $\mathrm{ON}$

10 L5L 1C6

11 Canada

12 tel: 905-828-5365; fax: 905-828-3792

13 e-mail: andrewm.macdonald@utoronto.ca

14 2e-mail: peter.kotanen@utoronto.ca

15

$16 *$ Author for correspondence

17

18 Length: 5906 words introduction-references; 6843 overall; 247 words abstract

19 


\section{Abstract}

Common ragweed (Ambrosia artemisiifolia) is an abundant weed in its native North

22 America, despite supporting a wide range of natural enemies. Here, we tested whether these

23 enemies have significant impacts on the performance of this plant in its native range. We

24 excluded enemies from the three principal life-history stages (seed, seedling and adult) of this

25 annual in a series of field experiments; at the adult stage, we also manipulated soil disturbance

26 and conspecific density. We then measured the consequences of these treatments for growth,

27 survival, and reproduction.

28 Excluding fungi and vertebrate granivores from seeds on the soil surface did not increase

29 germination relative to control plots. Seedling survivorship was only slightly increased by the

30 exclusion of molluscs and other herbivores. Insecticide reduced damage to leaves of adult plants,

31 but did not improve growth or reproduction. Growth and survivorship of adults were strongly

32 increased by disturbance, while higher conspecific density reduced performance in disturbed

33 plots.

34 These results indicate ragweed is insensitive to attack by many of its natural enemies,

35 helping to explain its native-range success. As well, they suggest that even though ragweed lost

36 most of its insect folivores while invading Europe, escape from these enemies is unlikely to have

37 provided a significant demographic advantage; instead, disturbance is likely to have been a much

38 more important factor in its invasion. Escape from enemies should not be assumed to explain the

39 success of exotic species unless improved performance also can be demonstrated; native-range

40 studies can help achieve this goal.

41 Key words: Ambrosia artemisiifolia, biological invasions, disturbance, Enemy Release

42 Hypothesis, natural enemies 


\section{Introduction}

Natural enemies have the potential to control populations of plants (Maron and Crone 2006); nonetheless, attack by enemies often fails to prevent weedy species from reaching

46 problem levels. One such example is provided by common ragweed (Ambrosia artemisiifolia,

47 hereafter "ragweed" or "Ambrosia"). This North American annual is highly abundant in its native

48 range, and is considered a severe weed of agricultural and urban areas as well as a principal

49 source of pollen allergies (Bassett and Teresmae 1962; Bassett and Crompton 1975; Teshler et al.

50 2002; Ziska et al. 2007), despite supporting a rich herbivore community including both

51 generalists and specialists (Futuyma and McCafferty 1990; Funk et al. 1995; Teshler et al. 2002;

52 MacKay and Kotanen 2008). These observations suggest that ragweed may respond weakly to

53 natural levels of damage by its enemies; existing studies provide indirect evidence both

54 supporting (Genton et al. 2005a; MacKay and Kotanen 2008) and apparently contradicting

55 (Throop 2005) this suggestion. However, there still has been no direct, manipulative test of the

56 effects of natural levels of herbivore damage to ragweed. Information about ragweed's response to natural enemies might help to explain its

58 invasiveness, or to rule out potential explanations. This plant has been widely introduced

59 throughout Eurasia, and now is abundant in parts of both eastern and western Europe, where it is

60 considered a severe problem (Kiss 2007). Ambrosia is much less attacked by enemies in its

61 invaded European range than in North America (Genton et al. 2005a). This would seem to

62 suggest invasive populations have benefitted as predicted by the Enemy Release Hypothesis

63 (Elton 1958; Keane and Crawley 2002; Torchin and Mitchell 2004; Liu and Stiling 2006), which

64 suggests that introduced plants are able to become invasive because their usual herbivores and

65 pathogens are absent in their new range. However, this explanation assumes that invaders

66 previously were limited by enemies within their home range, so that escaping these enemies 
during invasion provides a significant demographic benefit (Maron and Vilà 2001; Colautti et al. 2004; Hierro et al. 2005). The limiting effects of natural enemies on invaders therefore need to be studied in their native range (Guo 2006), as well as in invaded areas (Hierro et al. 2005). If a plant such as ragweed is not susceptible to control by enemies even in its native range, then its success in invaded regions must be explained by other factors (Maron and Vilà 2001). consequences for a population (Halpern and Underwood 2006; Mitchell et al. 2006). Therefore, to understand the importance of biotic interactions to Ambrosia, we excluded enemies in a series of field experiments from all three major stages of this annual's life cycle: seeds (technically achenes), seedlings and adult plants. We also manipulated disturbance and intraspecific density to investigate whether these interacted with herbivory to affect reproduction, growth, and survival at the adult stage. Disturbance and population density might be important both because herbivores could respond in a density-dependent fashion, and because herbivory could make plants less able

80 to compete with either conspecifics or surrounding vegetation (Halpern and Underwood 2006).

81 Together, our experiments represent the most complete study to date of ragweed's responses to its 82 natural enemies.

\section{Materials and Methods}

$84 \quad$ Site and study species

85 These experiments were conducted at the Koffler Scientific Reserve (KSR) at Joker's Hill, 86 a 350 ha field station owned by the University of Toronto and situated 50km north of Toronto,

87 Ontario (44 03'N, 79 29'W: http://www.ksr.utoronto.ca). Plots were established in old fields

88 dominated by perennial vegetation, notably Bromus inermis Leyss. and Solidago cf. canadensis.

89 This site has previously hosted other ragweed research, including MacKay and Kotanen (2008) 90 and components of Genton et al. (1995). 
91 Ragweed is common at the site in general and around our experimental plots in particular.

92 Plants are scarce in well-vegetated old fields, but reach high densities in recently-disturbed sites

93 such as plowed fields and roadsides. This species is highly disturbance-dependent (Allard 1943;

94 Bazzaz 1968; Bazzaz and Mezga 1973; Bazzaz 1974; Kosola and Gross 1999; Fumanal et al.

95 2008): its growth is strongly suppressed by shade (Raynal and Bazzaz 1975; Paquin and Aarssen

962004 ) and by root competition (Kosola and Gross 1999). The competitive effect on ragweed is so

97 pronounced that it has been suggested that competitors be included in biological control efforts

98 (Teshler et al. 2002).

99 Ragweed is frequently attacked by numerous species at our study site, including leaf-

100 chewing insects (Noctuidae: Tarachidia candefacta Hbn., Tarachidia erastrioides Hbn.;

101 Chrysomelidae: Zygogramma suturalis F., Systena blanda Mels.), stem-galling moths

102 (Tortricidae: Epiblema sp.), invertebrate and vertebrate seed and seedling predators (Carabidae:

103 Harpalis sp., rodents: Microtus pennsylvanicus (Ord), Peromyscus leucopus (Raf.)), and snails

104 (MacKay and Kotanen 2008); Ophraella spp. are uncommon at our site. Data from France

105 indicate that this plant has escaped most of these enemies during its invasion (Genton et al.

106 2005a); however, it is not clear that this has resulted in substantially improved performance or

107 higher population densities as might be expected if this escape led to a marked demographic

108 benefit. Although it is likely that populations in other regions of North America are attacked by

109 different suites of enemies, French populations seem to have originated from multiple sources,

110 potentially including Ontario populations (Genton et al. 1995a,b); thus, there is no reason to

111 believe our study site is an any way unrepresentative.

112 Experimental design

113 Seed survival

114 The effects of vertebrate (bird and mammal) granivory and fungal pathogens on seed 
115 mortality were assessed in a seed survival experiment. We established this experiment in early

116 November 2007, just after natural ragweed plants had dispersed seeds, using a mixture of seeds

117 collected in 2005 from four mother plants from each of 10 populations in Southern Ontario. We

118 ploughed six blocks (ca. 4m x 20m), and within each we marked nine small plots (approx. $10 \mathrm{~cm}$

$119 \mathrm{x} 10 \mathrm{~cm}$, in a 3x3 grid) separated from one another and the block's edge by a 1m buffer. Within

120 each plot we scattered 10 seeds on the ground surface. Adding these seeds in November ensured

121 that they would have been naturally cold-stratified before germination began next spring. Plots

122 were then randomly assigned one of three nested treatments: control (no treatment), cage

123 protection, and cage protection plus fungicide addition. The cages had a mesh size of approx.

$1241 \mathrm{~cm}^{2}$ and were meant to exclude large (vertebrate) granivores, but not granivorous insects, and

125 only minimally reduced light intensity. Fungal seed pathogens were controlled by soaking seeds

126 and surrounding soil with a 10g/L solution of Captan (Zeneca Agro, Stoney Creek, ON, Canada,

127 a heterocyclic phthalimide fungicide which is very effective against Oomycetes, Ascomycetes,

128 and Basidiomycetes (Sharvelle 1961; Torgeson 1969) and has been successfully used at this site

129 to exclude fungal pathogens from seeds (e.g., Blaney and Kotanen 2001; Schafer and Kotanen

130 2003). Low densities of seeds do occur in the soil in previously undisturbed sites; however, since

131 we treated soil (by fungicide addition or caging) rather than only treating our added seeds, any

132 pre-existing seeds in the seed bank should have received the same protection as our added seeds.

133 MacKay and Kotanen (2008) also used similar methods to examine the effects of fungi on buried

134 seeds; however, our experiment represents a significant departure both in that it examines other

135 possible sources of mortality, and in that it simulates impacts on newly-dispersed seeds, rather

136 than seeds stored below-ground in the seed bank.

137 In May and June 2008, emerging seedlings were marked and censussed weekly; we counted 138 seedlings until the end of June, when new seedlings had stopped appearing. Our response 
139 variable is the number of germinated seeds; although such seedlings clearly survived the seed

140 stage, ungerminated seeds could have been moved by earthworms, washed away, or have entered

141 secondary dormancy (Baskin and Baskin 1980), and therefore cannot be presumed to have died.

\section{Seedling survival}

143 The effects of attack by slugs, snails, and other herbivores on seedling survival were tested

144 in a seedling survival experiment in spring 2008. On June 7, we transplanted wild ragweed

145 seedlings (approx 2-4cm high, with at least 2 pairs of adult leaves) from a population at KSR to

146 five of the blocks also used for the seed survival experiment. In each block we planted 10 rows of

1473 plots (approx. 10cm diameter) with ten ragweed seedlings per plot (300 plants/block). Three

148 nested treatments were then randomly applied within rows: control (no enemy exclusion),

149 aluminum barrier plus slug pellets (mollusc exclusion), and aluminum barrier, slug pellets, plus a

150 covering of $1 \mathrm{~mm}^{2}$ nylon netting (complete herbivore exclusion). We used about 60ml of slug

151 pellets per plot (Spectrum Brands IP inc., Brantford, Ontario); these contained 2.75\%

152 metaldehyde, which kills slugs and snails when ingested. Aluminum barriers were made of a

153 sheet of aluminum flashing open at the bottom and protruding a few $\mathrm{cm}$ from the soil; such

154 barriers are effective against molluscs with added protection from slug pellets (Schüder et al.

155 2003). Netting excluded all but the smallest herbivores, including most insects, but minimally

156 reduced light intensity. We counted the seedlings throughout the seedling stage (until June 25) to

157 determine the rate of seedling mortality from these enemies.

158 Adult survival and reproduction

159 This experiment was conducted twice at KSR, once in 2007 and again in 2008. In both

160 years we used seeds from the same populations as the seed survival experiment. The seeds were

161 stratified in moist soil at approx. $5^{\circ} \mathrm{C}$ for one week, before being transferred to cell packs filled 
162 with standard potting soil and germinated in the greenhouse on the campus of the University of

163 Toronto at Mississauga. When experimental plants had developed two pairs of adult leaves and

164 were 6-10 cm high (approximately matching the size of naturally-occurring plants in the field)

165 they were brought to the field site and allowed to acclimatize in a sheltered location for at least 3

166 nights.

167 In both years, 5 experimental blocks were marked within old field vegetation, each

168 containing twelve $1 \mathrm{~m}^{2}$ plots separated by about $2 \mathrm{~m}$. Blocks were at least $30 \mathrm{~m}$ apart. Each plot

169 within a block was randomly subjected to one of 8 factorial combinations of three treatments: a

170 conspecific density treatment ( 9 vs. 25 plants $/ \mathrm{m}^{2}$ ), an insect exclusion treatment (insecticide vs.

171 water spray), and a disturbance treatment (plots cleared of existing vegetation vs. not cleared).

172 Plots were disturbed by completely hand-removing existing sod and stirring the underlying soil;

173 this likely represents a less severe disturbance than agricultural ploughing, though it may more

174 completely remove the seed bank. In the conspecific density treatments, plants were laid out in a

175 grid with approximately equal distances between each other and from the edge of the plot.

176 Finally, in 2007, insects were excluded by spraying the upper and lower surfaces of all leaves

177 with a weekly spray of the insecticidal plant extract Rotenone (5\% Rotenone, 30ml in 3L water,

178 Wilson Laboratories, Dundas, ON). In 2008 we followed the same procedure, but used the

179 organophosphate pesticide Malathion (50\% Malathion, 25ml in 3L water, Wilson Laboratories,

180 Ontario). We changed the pesticide treatment because Rotenone proved less effective (see

181 Results). In both years control plots were sprayed with an equivalent amount of water.

182 In both years, the proportion of leaves with visible herbivore damage (tissue removal) and

183 two measures of plant size (plant height and leaf number) were measured in August, close to the

184 end of the growing season. We estimated the proportion of leaves damaged rather than leaf area

185 removed because the complex, dissected morphology of ragweed leaves makes it impossible to 
186 estimate the area of missing leaf segments. In 2007, damage and plant size were measured for all

187 plants; in 2008, they were measured for six randomly chosen focal individuals per plot, and the

188 proportion of plants attacked by stem borers was determined as well. As well, at the end of the

189 summer (September), when flowering was complete, stem biomass and fecundity were measured.

190 In 2007, fecundity was determined by counting all seeds on three randomly-chosen plants per

191 plot. In 2008, we estimated fecundity by weighing all seeds produced by each individual: a

192 regression of 38 plants subsampled from all treatments of one of our experimental blocks

193 indicated that weight is an excellent predictor of seed number (linear regression: $\mathrm{F}_{1,36}=947.94, \mathrm{P}$

$194<0.001, \mathrm{r}^{2}=0.96$, both variables log-transformed).

195 Statistical analyses

196 We tested for the effects of enemy exclusion on the number of germinated seeds and

197 surviving seedlings with randomized-block ANOVAs (Kirk 1995). To simplify our design, avoid

198 pseudoreplication, and improve estimates of damage, we first calculated the means of all within-

199 block replicates (3 for the seed experiment, 10 for the seedling experiment) and performed our

200 analysis on these; patterns of significance were essentially unchanged if individual plants were

201 instead used as datapoints. Block means were log-transformed to normalize residual variance,

202 and block was treated as a random effect in our analyses. In each experiment, we tested the $a$

203 priori hypothesis that a more complete exclusion of enemies would increase survival.

204 Specifically, we hypothesized the following ranks of magnitude in our response variables: control

205 < cage < cage \& fungicide (seeds germinating), control < barrier < barrier \& net (seedlings

206 surviving). The analysis of these ordered factors was conducted with orthogonal polynomial

207 contrasts (Sokal and Rohlf 1994; Quinn and Keough 2002).

208 For analyses of adult plants, we tested for treatment differences in plant size, fecundity, and 209 damage with randomized block factorial ANOVAs (Kirk 1995). All statistical models were 
210 mixed, including the three treatments (disturbance, density and pesticide spray) as fixed effects

211 and block as random. Again, we used plot means in our analyses; again, this did not qualitatively

212 alter our results. In contrast, survivorship and stem gall incidence were measured as proportions

213 of plants within each plot. We analyzed these data with Generalized Linear Mixed Models

214 (GLMM: Crawley 2007; Bolker 2008), using the same structure of fixed and random effects as in

215 the ANOVAs. To accommodate proportional data, the GLMM uses a logit link and assumes

216 binomial errors. The significance of terms was determined by simplifying the model and

217 checking for a significant $(\mathrm{p}<0.05)$ loss of explanatory power with a likelihood-ratio test. Two-

218 way interactions were not deleted sequentially but were replaced after testing, so that each

219 interaction was tested against a model containing all other 2-way interactions (Crawley 2007).

220 Analyses were performed in R 2.8.1 (R Development Core Team 2008).

\section{Results}

222 Seeds and seedlings

223 About $50 \%$ of seeds germinated in situ (out of 10 seeds, $4.78 \pm 0.5$, mean \pm SEM).

224 Protection from both vertebrate herbivores and fungi had no effect: by the end of June there were 225 no significant differences among treatments in the number of germinated seeds (Table 1).

226 Seedling survivorship was very high; between early and late June an average of 7.8 out of

22710 seedlings survived in each plot. Treatments differed significantly (at $\mathrm{P}=0.10$ ), and our $a$

228 priori hypothesis of increasing survivorship with increasing protection was supported (linear

229 contrast $\mathrm{P}=0.04$ ) (Table 1). Increasing levels of enemy exclusion (control, molluscs, all

230 herbivores) resulted in increasingly greater seedling survival: 7.14 $\pm 0.95,7.76 \pm 0.56$ and $8.6 \pm$

2310.44 of 10 seedlings, respectively. Excluding molluscs therefore created an $8.7 \%$ relative increase

232 in survivorship; excluding other herbivores added a further 10.8\%. 
In 2007, the proportion of leaves damaged was high: on average $81.9 \%$ of leaves in the

235 control treatment were damaged. This figure reflects the net herbivore damage from all sources;

236 the principal herbivores responsible are believed to be those listed in our Methods section. This

237 level of damage was greater than that reported by MacKay and Kotanen (2008), who found 40\%

238 to $58 \%$ of leaves were damaged, depending on the degree of isolation from conspecifics. Our

239 pesticide treatment was weakly effective, reducing relative damage by 16.7\% (Table 2, Fig. 1).

240 There was no significant pattern of increasing damage with density or disturbance, and no

241 significant interactions (Table 2, Fig. 1).

242 Survivorship over the summer was strongly enhanced by disturbance, with 93.5\% of plants

243 surviving in disturbed sites and 42.6\% in undisturbed sites (Fig. 2); GLMM model simplification

244 confirmed that survivorship increased in disturbed plots $(|z|=6.70, p<0.001)$, though neither

245 density nor pesticide had a significant effect ( $>$ > 0.05) (Fig. 2). Plant growth (number of leaves

246 and stem biomass) and fecundity were not affected by insecticide but significantly increased in

247 response to disturbance, and also showed a strong interaction with density (Table 2, Fig. 2).

248 Greater conspecific density was important only in the disturbed treatment, where it relatively

249 reduced average leaf number by $38.9 \%$, stem biomass by $67 \%$, and seed production by $74 \%$.

250 The following summer damage rates were much lower: on average, 33.4\% of leaves per

251 plant were damaged in control plots in 2008 (Fig. 1). Again, this figure represents net damage,

252 rather than damage by a specific herbivore. This level of damage was less than that reported by

253 MacKay and Kotanen (2008), but differences between treatments were much more extreme:

254 Malathion was very effective, reducing the relative damage level by 72\% (Table 2). However, in

255 contrast to 2007, we found significant interactions of insecticide application with both density

256 and disturbance: denser plots experienced relatively 31\% less leaf damage per plant in control 
257 plots only, while disturbance lowered leaf damage in both pesticide and control plots but had a

258 proportionally greater effect in pesticide-sprayed plots where overall damage rates were lower.

259 While stem galling (likely by Epiblema strenuata Walk.) also was effectively controlled by

260 Malathion (GLMM $|\mathrm{z}|=3.80, \mathrm{p}<0.001)$, average rates of attack across both herbivory treatments

261 instead were higher in disturbed plots $(|z|=4.06, \mathrm{P}<0.001)$, though this result depended on the

262 water controls (Fig. 3). Conspecific density did not have a significant effect on stem galling (P >

$2630.05)$.

264 Survivorship over the summer of 2008 was very high: only 10 focal plants died in the entire

265 year (4.2\% mortality), making it impossible to detect treatment effects on survivorship (Fig. 4).

266 However, plant growth and fecundity followed a pattern similar to the 2007 results (Table 2, Fig.

267 4). Disturbance strongly increased the number of leaves, stem biomass, and seed production.

268 Density had a clear effect only in disturbed plots, where it reduced average leaf number by

$26941.4 \%$, stem biomass by $63.8 \%$, and seed production by $65.6 \%$. Finally, insect exclusion, while

270 effective, did not affect either growth or fecundity.

\section{Discussion}

272 The major findings of our study are that enemies have i) no effect on seed germination, ii)

273 only a slight effect on seedling survivorship and iii) no effect on adult survivorship, growth or

274 fecundity. These results suggest that natural enemies are likely to be ineffective in controlling this

275 species even in its native range. As a result, enemy release is not likely to have encouraged its

276 invasiveness in Europe. Comparatively, disturbance is likely to be much more important than

277 herbivory for populations in both native and non-native regions.

278 Seed germination

279 Ragweed seeds have high survivorship between growing seasons (Baskin and Baskin 280 1980), and our results suggest that protection did not cause an increase in this already high rate. 
281 In fact, we probably underestimated survival, since at least some of the seeds that failed to

282 germinate likely remained dormant, or were moved out of the plot. We were unable to detect any

283 losses to vertebrate granivores, though these are known to be important for related species

284 (Harrison and Regnier 2003). As well, we failed to find evidence of fungal pathogens; MacKay

285 and Kotanen (2008) also failed to detect seed pathogens for ragweed, though they did provide

286 evidence that feedback by soil pathogens may reduce plant growth over time. We did not attempt

287 to manipulate seed losses to insects, but post-dispersal insect predation may be low because of

288 ragweed's hard pericarp: once mature, this is very difficult to crack and resists breaking by even

289 strong-jawed organisms such as crickets and ground beetles (pers. obs.). In contrast, pre-dispersal

290 seeds at this site are vulnerable to granivores such as Harpalus spp. (Coleoptera: Carabidae)

291 (MacKay and Kotanen 2008).

292 Our study contrasts with work in a related species, Ambrosia trifida (Harrison and Regnier

293 2003): in this species, rodent and invertebrate seed predation was as high as $88 \%$. We may have

294 underestimated rodent predation since seed mortality is likely to be low in disturbed areas where

295 small mammals themselves risk predation (e.g., Manson and Stiles 1998). Nonetheless, Harrison

296 and Regnier (2003) point out that even with a high rate of seed predation, population limitation of

297 A. trifida by this means alone is unlikely; our results suggest that this is even more true for $A$.

298 artemisiifolia.

299 Seedling survival

$300 \quad$ Although excluding herbivores increased survival at the seedling stage, this effect was

301 small, and the survivorship of unprotected seedlings remained high. This is despite the local

302 abundance of snails (MacKay and Kotanen 2003), which can have a very large effect on seedling

303 survival (e.g., Hill and Silvertown 1997; Ehrlen 2003); as well, many leaf-eating insects are

304 present in spring, including overwintered adults and newly-laid eggs of the specialist 
Zygogramma suturalis F. Since ragweed plants, once grown, are highly tolerant to leaf damage

306 (see below), high seedling survivorship will likely result in dense adult populations and a

307 correspondingly high level of seed production. Our results from this experiment are consistent

308 with our observations of germinated seeds in the seed protection experiment: of 257 germinated

309 seeds, only 8 resulting seedlings died before the end of June.

310 Adult survival and reproduction

311 Two years of data cannot capture the full range of variability in herbivore damage;

312 nonetheless, the contrast between 2007 and 2008 gives some indication of the magnitude of

313 variability that may be expected. In both years, ragweed plants were insensitive to reductions in

314 natural levels of herbivory: neither when unprotected plants were heavily damaged in 2007, nor

315 when we were able to better control damage levels in 2008, did we find treatment effects on

316 growth or reproduction. The absence of strong enemy effects at the adult stage was robust to

317 manipulations of density and the presence of competitors.

318 These results are consistent with most previous evidence, which has not consistently

319 suggested a strong negative effect of herbivores. For instance, in ragweed's native region,

320 MacKay and Kotanen (2008) but did not find evidence of improved performance by less-

321 damaged plants; however herbivores were not experimentally removed from plants; thus,

322 variation in damage was relatively small, and likely was confounded with other factors such as

323 habitat and host-choice. In fact, some measures of damage were positively correlated with

324 performance, likely because larger plants were more attractive to herbivores. In both native and

325 invaded regions, Genton et al. (2005a) found foliar damage was negatively correlated with plant

326 height, but this did not result in greater biomass in non-native areas despite greatly reduced

327 herbivore pressure; again, herbivore pressure was not directly manipulated. Irwin and Aarssen

328 (1996) also reported that ragweed was very tolerant of artificial apical meristem removal, at least 
329 in open sites. On the other hand, Throop (2005) reported that damage by the leaf beetle

330 Ophraella communa LeSage significantly reduced seed production (but not vegetative growth); a 331 specialist aphid (Uroleucon tuataiae Olive) caused much milder damage. It is possible that $O$.

332 communa is a more damaging herbivore than those observed in our study; however, a possible

333 bias may result from the methods used by Throop (2005): multiple beetles were added to caged

334 experimental plants, potentially resulting in unusually elevated levels of damage. No information

335 was provided regarding natural beetle densities of levels of herbivory, though the author noted

336 that O. communa can cause high levels of damage. Even so, a field study of spatial patterns of

337 abundance of both ragweed and O. communa in Japan suggested that even large numbers of

338 beetles were ineffective at reducing population density (Yamanaka et al. 2007). Ours remains the

339 only study to experimentally document the effects of natural levels of herbivore damage to

340 ragweed.

$341 \quad$ Disturbance effects

342 Ragweed is a disturbance-dependent ruderal (Bazzaz 1968; Bazzaz and Mezga 1973;

343 Kosola and Gross 1999; Ziska et al. 2007; Fumanal et al. 2008): every measurement of

344 performance was higher when our plots were cleared of sod. Interestingly, clearing vegetation

345 also reduced the amount of leaf damage plants incurred, at least in 2008; this could have

346 contributed to the improved performance of plants in these plots. However, any such effect would

347 be confounded with the direct effects of reduced competition, again indicating a need to directly

348 assess the effects of herbivores by experimental removal; as indicated above, such tests failed to

349 find a direct benefit of herbivore exclusion. Historically, this strong response to disturbance is

350 believed to have resulted in rapid growth of ragweed populations over much of eastern North

351 America following deforestation and agriculture by European settlers, as indicated by pollen

352 records (Bassett and Terasmae 1962; McAndrews 1988). Likewise, invasion of disturbed sites is 
353 believed to be largely responsible for ragweed's successful invasion of Europe (Chauvel et al.

354 2006; Kiss 2007; Fumanal et al. 2008).

355 Density-dependence

356 Ragweed can grow at very high densities. The highest density we used $\left(25\right.$ plants $\left./ \mathrm{m}^{2}\right)$ is 357 representative of natural many populations (e.g., Foster et al. 1980); in comparison, we can

358 consider 9 plants $/ \mathrm{m}^{2}$ treatment to represent reduced intraspecific competition, as might be found

359 in newly-founded populations. Higher conspecific densities decreased most measures of plant

360 performance, including reproduction, but only when plots were disturbed. In such disturbed

361 locations, individuals were able to grow to sufficiently large sizes to directly interact with one

362 another, whereas interspecific competition kept individual plants too small to interact in

363 undisturbed sites, and likely masked any intraspecific effects. Nonetheless, while density-

364 dependence in disturbed sites makes population regulation possible in principle (Halpern and

365 Underwood 2006), the very strong direct response of ragweed to disturbance is likely to greatly

366 reduce this potential control.

367 Implications

368 Our results indicate that natural enemies have weak effects on ragweed even in its native 369 range. Unless damage in our area is atypically low, this also suggests that escape from its natural

370 enemies may have played only a minor role in ragweed's invasion of Europe. Instead, even

371 though European populations experience much lower levels of herbivore damage than Ontario

372 populations (Genton et al. 2005a), the benefits of this escape may be minor. This interpretation

373 agrees with earlier results correlating damage with performance (Genton et al. 2005a; MacKay

374 and Kotanen 2008). As well, this may suggest why European ragweed apparently has not lost

375 anti-herbivore defences (Genton et al. 2005a), contrary to the Evolution of Increased Competitive

376 Ability Hypothesis (Blossey and Nötzold 1995): if herbivore pressures were small even in native 
areas, one would expect little evolutionary response when these pressures were removed.

378 Our results also have implications for biological control. In both its native (Teshler et al.

379 2002) and invaded range (Igrc 1995; Reznik et al. 1994; Kiss 2007), there have been numerous

380 attempts to control Ambrosia artemisiifolia by introducing ragweed-feeding invertebrates, but

381 few successes. There likely are a number of reasons for this result, including failure of biocontrol

382 organisms to establish viable populations; however, our experiments suggest that one factor

383 simply may be a weak effect of most natural enemies of plant performance. Even in its native

384 range, natural consumer damage did not significantly reduce Ambrosia survival or seed

385 production; consequently, biological control programs seem unlikely to provide an effective

386 means of control unless they can produce damage well in excess of the natural levels we have

387 documented.

\section{Acknowledgments}

389 M. Saunders, K.A. Judge, L.J. Robson, M. Lerdau, and two anonymous reviewers for useful

390 comments. A. Simonsen, R. Dinnage, Z. Burivalova, R. MacKenzie, A.M. Petersen, V. Pham and

391 especially K. Kostyukova for helpful field work. J. Stinchcombe and S.C.H. Barrett for advice,

392 Art Weis and KSR for logistical support. This work would have been impossible without the

393 donation of Koffler Scientific Reserve to the University of Toronto by the Koffler family. This

394 work was supported by a Natural Sciences and Engineering Research Council of Canada PGS to

395 A.A.M.M. and a Discovery Grant to P.M.K. These experiments comply with all local laws. 


\section{References}

398 Allard HA (1943) The North American ragweeds and their occurrence in other parts of the world.

399 Science 98: 292-294

400 Baskin JM, Baskin CC (1980) Ecophysiology of secondary dormancy in seeds of Ambrosia

$401 \quad$ artemisiifolia. Ecology 61: 475-480

402 Baskin CC, Baskin JM (1998) Seeds: ecology, biogeography, and evolution of dormancy and

403 germination. Academic Press, San Diego

404 Bassett IJ, Crompton CW (1975) The biology of Canadian weeds. 11. Ambrosia artemisiifolia L.

405 and Ambrosia psilostachya DC. Can J Plant Sci 2: 463-476

406 Bassett IJ, Terasmae J (1962) Ragweeds, Ambrosia species, in Canada and their history in

407 postglacial time. Can J Bot 40: 141-150

408 Bazzaz FA (1968) Succession on abandoned fields in the Shawnee Hills, southern Illinois.

$409 \quad$ Ecology 49: 924-936

410 Bazzaz FA (1974) Ecophysiology of Ambrosia artemisiifolia: a successional dominant. Ecology

$411 \quad 55: 112-119$

412 Bazzaz FA, Mezga DM (1973) Primary productivity and microenvironment in an Ambrosia

413 dominated old-field. Am Midl Nat 90: 70-78

414 Blaney CS, Kotanen PM (2001) Post-dispersal losses to seed predators: an experimental

415 comparison of native and exotic old field plants. Can J Bot 79: 284-292

416 Blossey B, Nötzold R (1995) Evolution of increased competitive ability in invasive

417 nonindigenous plants: a hypothesis. J Ecol 83: 887-889

418 Bolker BM (2008) Ecological models and data in R. Princeton University Press, Princeton

419 Cadotte MW, Murray BR, Lovett-Doust J (2006) Ecological patterns and biological invasions:

420 using regional species inventories in macroecology. Biol Inv 8: 809-821 
421 Chauvel B, Dessaint F, Cardinal-Legrand C, Bretagnolle F (2006) The historical spread of

422 Ambrosia artemisiifolia L. in France from herbarium records. J Biogeog 33: 665-673

423 Colautti RI, Ricciardi A, Grigorovich IA, MacIsaac HJ (2004) Is invasion success explained by

424 the enemy release hypothesis? Ecol Lett 7: 721-733

425 Crawley MJ (2007) The R book. Wiley, Chichester

426 Ehrlen J (2003) Fitness components versus total demographic effects: Evaluating herbivore

427 impacts on a perennial herb. Am Nat 162: 796-810

428 Elton CS (1958) The ecology of invasions by animals and plants. Methuen, London

429 Foster MM, Vitousek PM, Randolph PA (1980) The effects of ragweed (Ambrosia artemisiifolia

430 L.) on nutrient cycling in a 1st-year old-field. Am Midl Nat 103: 106-113

431 Fumanal B, Girod C, Fried G, Bretagnolle F, Chauvel B (2008) Can the large ecological

432 amplitude of Ambrosia artemisiifolia explain its invasive success in France? Weed Res 48: 349-

$433 \quad 359$

434 Funk DJ, Futuyma D, Ortí G, Meyer A (1995) A history of host associations and evolutionary

435 diversification for Ophraella (Coleoptera: Chrysomelidae): new evidence from mitochondrial

436 DNA. Evolution 49: 1008-1017

437 Futuyma DJ, McCafferty SS (1990) Phylogeny and the evolution of host plant associations in the

438 leaf beetle genus Ophraella (Coleoptera: Chrysomelidae). Evolution 44: 1885-1913.

439 Genton BJ, Kotanen PM, Cheptou P-O, Adolphe C, Shykoff JA (2005a) Enemy release but no

440 evolutionary loss of defence during ragweed invasion of France: an inter-continental reciprocal

441 transplant experiment. Oecologia 146: 404-414

442 Genton BJ, Shykoff JA, Giraud T (2005b) High genetic diversity in French invasive populations

443 of common ragweed, Ambrosia artemisiifolia, as a result of multiple sources of introduction.

$444 \quad$ Mol Ecol 14: 4275-4285 
445 Guo Q (2006) Intercontinental biotic invasions: what can we learn from native populations and

446 habitats? Biol Inv 8: 1451-1459

447 Halpern SL, Underwood N (2006) Approaches for testing herbivore effects on plant population

448 dynamics. J Appl Ecol 43: 922-929

449 Harrison SK, Regnier EE (2003) Postdispersal predation of giant ragweed (Ambrosia trifida) seed

$450 \quad$ in no-tillage corn. Weed Sci 51: 955-964

451 Hierro LJ, Maron JL, Callaway RM (2005) A biogeographical approach to plant invasions: the

452 importance of studying exotics in their introduced and native range. J Ecol 93: 5-15

453 Hill BHC, Silvertown J (1997) Higher-order interaction between molluscs and sheep affecting

454 seedling numbers in grassland. Acta Oecologica 18: 587-596

455 Igrc J, Deloach CJ, Zlof V (1995) Release and establishment of Zygogramma suturalis F

456 (Coleoptera, Chrysomelidae) in Croatia for control of common ragweed (Ambrosia

457 artemisiifolia L). Biological Control 5: 203-208

458 Irwin DL, Aarssen LW (1996) Testing for cost of apical dominance in vegetation: a field study of

459 three species. Ann Bot Fennici 33: 123-128

460 Keane RM, Crawley MJ (2002) Exotic plant invasions and the enemy release hypothesis. Trends

$461 \quad$ Ecol Evol 17: 164-170

462 Kirk RE (1995) Experimental design: procedures for the behavioural sciences (3rd edn.)

463 Brooks/Cole, Pacific Grove

464 Kiss L (2007) Why is biological control of common ragweed, the most allergenic weed in Eastern

465 Europe, still only a hope? In: Vincent C, Goettel MS, Lazarovits G (eds). Biological control: a

466 global perspective. CABI, Wallingford, pp. 80-91.

467 Kosola KR, Gross KL (1999) Resource competition and suppression of plants colonizing early 468 successional old fields. Oecologia 118: 69-75 
469 Liu H \& Stiling P (2006) Testing the enemy release hypothesis: a review and meta-analysis. Biol $470 \quad$ Inv 8: $1535-1545$

471 MacKay J, Kotanen PM (2008) Local escape of an invasive plant, common ragweed (Ambrosia

472 artemisiifolia L.), from above-ground and below-ground enemies in its native area. J Ecol 96: $473 \quad 1152-1161$

474 Manson RH, Stiles EW (1998) Links between microhabitat preferences and seed predation by 475 small mammals in old fields. Oikos 82: 37-50

476 Maron JL, Crone E (2006) Herbivory: effects on plant abundance, distribution and population 477 growth. Proc R Soc B 273: 2575-2584

478 Maron JL, Vilà M (2001) When do herbivores affect plant invasion? Evidence for the natural 479 enemies and biotic resistance hypotheses. Oikos 95: 361-373

480 McAndrews JH (1988) Human disturbance of North American forests and grasslands: the fossil

481 pollen record. In: Huntley B, Webb T III (eds) Vegetation history. Kluwer Academic Publishers. 482 Dordrecht, pp 673-697

483 Mitchell CE, Agrawal AA, Bever JD, Gilbert GS, Hufbauer RA, Klironomos JN, Maron JL, 484 Morris, WF, Parker IM, Power AG, Seabloom EW, Torchin ME, Vázquez DP (2006) Biotic 485 interactions and plant invasions. Ecol Lett 9: 726-740

486 Paquin V, Aarssen LW (2004) Allometric gender allocation in Ambrosia artemisiifolia 487 (Asteraceae) has adaptive plasticity. Am J Bot 91: 430-438

488 Quinn GP, Keough MJ (2002) Experimental design and data analysis for biologists. Cambridge $489 \quad$ University Press, Cambridge

490 R Development Core Team (2008) R: A language and environment for statistical computing. R 491 Foundation for Statistical Computing, Vienna 492 Raynal DJ, Bazzaz FA (1975) Interference of winter annuals with Ambrosia artemisiifolia in 
493 early successional fields. Ecology 56: 35-49

494 Reznik SY, Belokobyl'skiy SA, Lobanov AL (1994) Weed and herbivorous insect population

495 densities at the broad spatial scale: Ambrosia artemisiifolia L. and Zygogramma suturalis F.

496 (Col., Chrysomelidae). J Appl Ent 118: 1-9

497 Schafer M, Kotanen PM (2003) The influence of soil moisture on losses of buried seeds to fungi.

498 Acta Oecologica 24: 255-263

499 Schüder I, Port G, Bennison J (2003) Barriers, repellents and antifeedants for slug and snail

$500 \quad$ control. Crop Protection 22: 1033-1038

501 Sharvelle EG (1961) The nature and uses of modern fungicides. Burgess Publishing, Minneapolis

502 Sokal RR, Rohlf FJ (1994) Biometry: the principles and practices of statistics in biological

503 research (3rd edn.). W.H. Freeman, New York

504 Stevens MHH, Carson WP (1999) Plant density determines species richness along an

505 experimental fertility gradient. Ecology 80: 455-465

506 Teshler MP, DiTommaso A, Gagnon JA, Watson AK (2002) Ambrosia artemisiifolia L. common

507 ragweed (Asteraceae). In: Mason PG, Huber JT (eds). Biological control programs in Canada

508 1981-2000. CABI, Wallingford, pp. 290-294

509 Throop HL (2005) Nitrogen deposition and herbivory affect biomass production and allocation in

$510 \quad$ an annual plant. Oikos 111: 91-100.

511 Torchin ME, Mitchell CE (2004) Parasites, pathogens, and invasions by plants and animals. Front

$512 \quad$ Ecol Environ 2: 183-190

513 Torgeson DC (1969) Fungicides: an advanced treatise, vol. II. Academic Press, New York

514 Yamanaka T, Tanaka K, Otuka A, Bjørnstad ON (2007) Detecting spatial interactions in the

515 ragweed (Ambrosia artemisiifolia L.) and the ragweed beetle (Ophraella communa LeSage)

$516 \quad$ populations. Ecol Res 22: 185-196 
517 Ziska LH, George K, Frenz DA (2007) Establishment and persistence of common ragweed

518 (Ambrosia artemisiifolia L.) in disturbed soil as a function of an urban-rural macro-

519 environment. Global Change Biology 13: 266-274 
520 Table 1. Effects of protection on seed germination and seedling survival. For seed germination,

521 ordered treatments levels are: no protection (control), cage (vertebrate exclusion), and cage +

522 fungicide (vertebrate \& fungal exclusion); for seedlings, they are: no protection (control), barrier

523 + slug pellets (mollusc exclusion), and barrier + slug pellets + netting (complete herbivore

524 exclusion). ANOVAs have been used to partition variation into orthogonal polynomial contrasts

525 to test for an increase in survivorship with more complete enemy exclusion. Data were log-

526 transformed to normalize variance

\begin{tabular}{cllllllll}
\hline & \multicolumn{3}{c}{ Seed germination } & \multicolumn{4}{c}{ Seedling survival } \\
Source & df & MS & F & p & df & MS & F & p \\
\hline Treatment & 2 & 0.025 & 0.354 & 0.71 & 2 & 0.06 & 3.13 & 0.10 \\
Linear & 1 & 0.031 & 0.442 & 0.52 & 1 & 0.12 & 6.25 & 0.04 \\
Quadratic & 1 & 0.019 & 0.265 & 0.62 & 1 & $<0.01$ & $<0.01$ & 0.97 \\
Residual & 10 & 0.071 & & & 8 & 0.16 & & \\
\hline
\end{tabular}

527 
528 Table 2. Effects of experimental treatments on adult plants. Factorial ANOVAs have been used to

529 examine the effects of conspecific density, disturbance, and insecticide application. Leaf number

530 and seed number were log-transformed before analysis to normalize residuals, as was 2008 stem

531 biomass. F-statistics and p-values are shown in bold typeface when significant

\begin{tabular}{|c|c|c|c|c|c|c|c|c|c|}
\hline \multirow[b]{2}{*}{ Year } & \multirow[b]{2}{*}{ Source } & \multicolumn{2}{|c|}{ Damage } & \multicolumn{2}{|c|}{ Leaf Number } & \multicolumn{2}{|c|}{ Stem Biomass } & \multicolumn{2}{|c|}{ Fecundity $^{1}$} \\
\hline & & $\mathrm{F}_{1,28}$ & $\mathrm{p}$ & $\mathrm{F}_{1,28}$ & $\mathrm{p}$ & $\mathrm{F}_{1,28}$ & $\mathrm{p}$ & $\mathrm{F}_{1,28}$ & $\mathrm{p}$ \\
\hline \multirow[t]{8}{*}{2007} & Density & 1.25 & 0.28 & 77.19 & $<0.01$ & 62.51 & $<0.01$ & 2.73 & 0.11 \\
\hline & Disturbance & $<0.01$ & 0.97 & 1109.8 & $<0.01$ & 62.18 & $<0.01$ & 64.87 & $<0.01$ \\
\hline & Insecticide & 6.35 & 0.02 & 2.95 & 0.10 & $<0.01$ & 0.99 & 0.72 & 0.40 \\
\hline & Density x Disturbance & 1.26 & 0.27 & 5.72 & 0.03 & 16.61 & $<0.01$ & 5.23 & 0.03 \\
\hline & Density x Insecticide & 0.20 & 0.66 & 1.09 & 0.31 & 0.03 & 0.86 & 0.40 & 0.53 \\
\hline & Disturbance $\mathrm{x}$ Insecticide & 0.16 & 0.69 & 0.21 & 0.65 & 0.18 & 0.67 & 0.09 & 0.76 \\
\hline & Density x Disturbance x & 0.07 & 0.79 & 2.31 & 0.14 & 0.11 & 0.74 & 1.11 & 0.30 \\
\hline & Insecticide & & & & & & & & \\
\hline \multirow[t]{7}{*}{2008} & Density & 5.57 & 0.03 & 2.12 & 0.16 & 12.97 & $<0.01$ & 2.21 & 0.15 \\
\hline & Disturbance & 45.12 & $<0.01$ & 152.05 & $<0.01$ & 235.96 & $<0.01$ & 56.34 & $<0.01$ \\
\hline & Insecticide & 84.62 & $<0.01$ & 1.98 & 0.17 & 0.12 & 0.73 & 2.16 & 0.15 \\
\hline & Density x Disturbance & 1.05 & 0.31 & 6.95 & 0.01 & 19.77 & $<0.01$ & 10.39 & $<0.01$ \\
\hline & Density x Insecticide & 5.83 & 0.02 & 0.04 & 0.83 & 0.37 & 0.55 & 0.29 & 0.59 \\
\hline & Disturbance x Insecticide & 5.53 & 0.03 & 4.29 & 0.05 & 0.00 & 0.96 & 0.54 & 0.47 \\
\hline & Density x Disturbance x & 1.36 & 0.25 & 0.84 & 0.37 & 1.03 & 0.32 & 0.53 & 0.47 \\
\hline
\end{tabular}




\section{Figure legends}

535 Fig. 1 Leaf damage to adult plants during the summer of (A) 2007 and (B) 2008.

536 Treatments are disturbed vs. undisturbed plots, high vs. low conspecific density, and

537 insecticide application (2007: Rotenone; 2008: Malathion) vs. controls (water). Points

538 are means $\pm \mathrm{SE}(\mathrm{n}=5)$; see Table 2 for ANOVA results

539 Fig. 2 Performance of adult plants during the summer of 2007. Treatments are

540 disturbed vs. undisturbed plots, high vs. low conspecific density, and insecticide

541 application (Rotenone) vs. controls (water). Disturbed plots are indicated by filled

542 circles; undisturbed controls by open circles. Points are means \pm SE $(n=5)$. See Table

5432 for ANOVA results (growth, reproduction); GLMM analysis indicated survival was

544 increased by disturbance $(\mathrm{P}<0.001)$

545 Fig. 3 The incidence of stem-galling insects on adult plants during the summer of

546 2008. Treatments are disturbed vs. undisturbed plots, high vs. low conspecific density,

547 and insecticide application (Malathion) vs. controls (water). Points are means \pm SE (n

548 =5). GLMM analysis indicated galling was increased by disturbance, but decreased by

549 insecticide application $(\mathrm{P}<0.001)$

550 Fig. 4 Performance of adult plants during the summer of 2008. Treatments are

551 disturbed vs. undisturbed plots, high vs. low conspecific density, and insecticide

552 application (Malathion) vs. controls (water). Disturbed plots are indicated by filled

553 circles; undisturbed controls by open circles. Points are means \pm SE $(n=5)$; see Table

5542 for ANOVA results (growth, reproduction); survival was not analyzed because almost

555 all plants survived

556 
$557 \quad$ Figure 1.
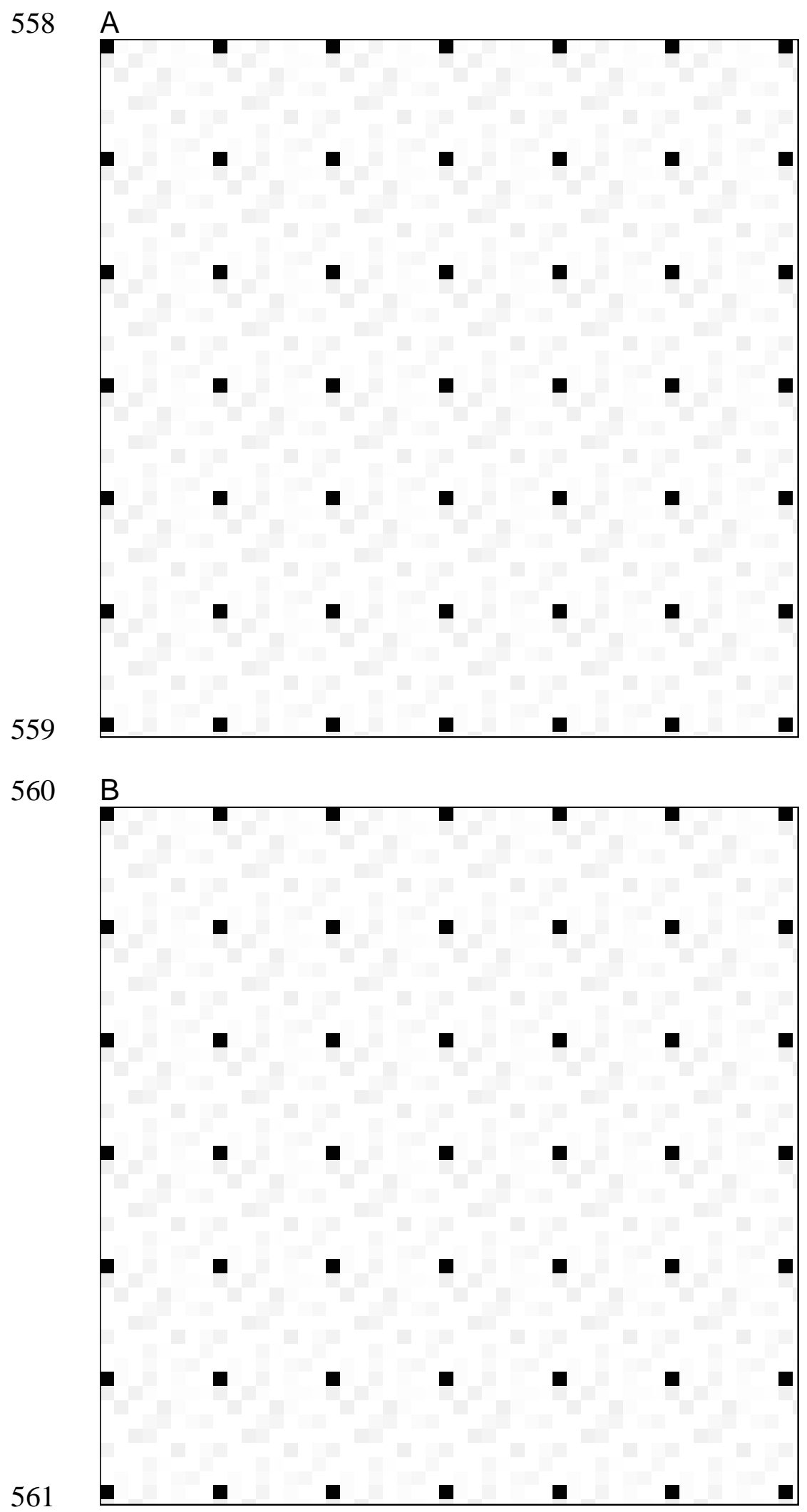

562 
$563 \quad$ Figure 2.

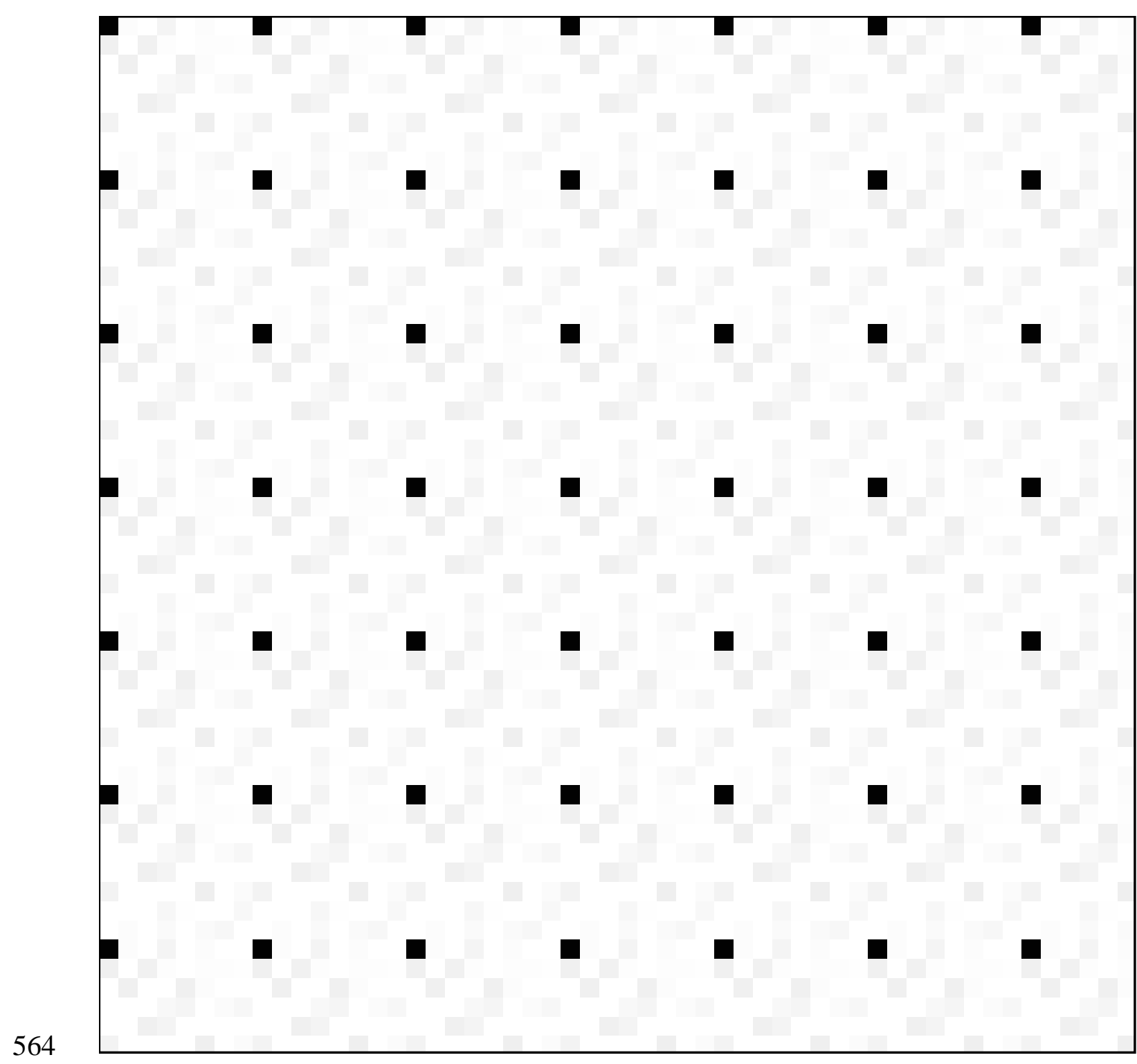

565 
$566 \quad$ Figure 3.

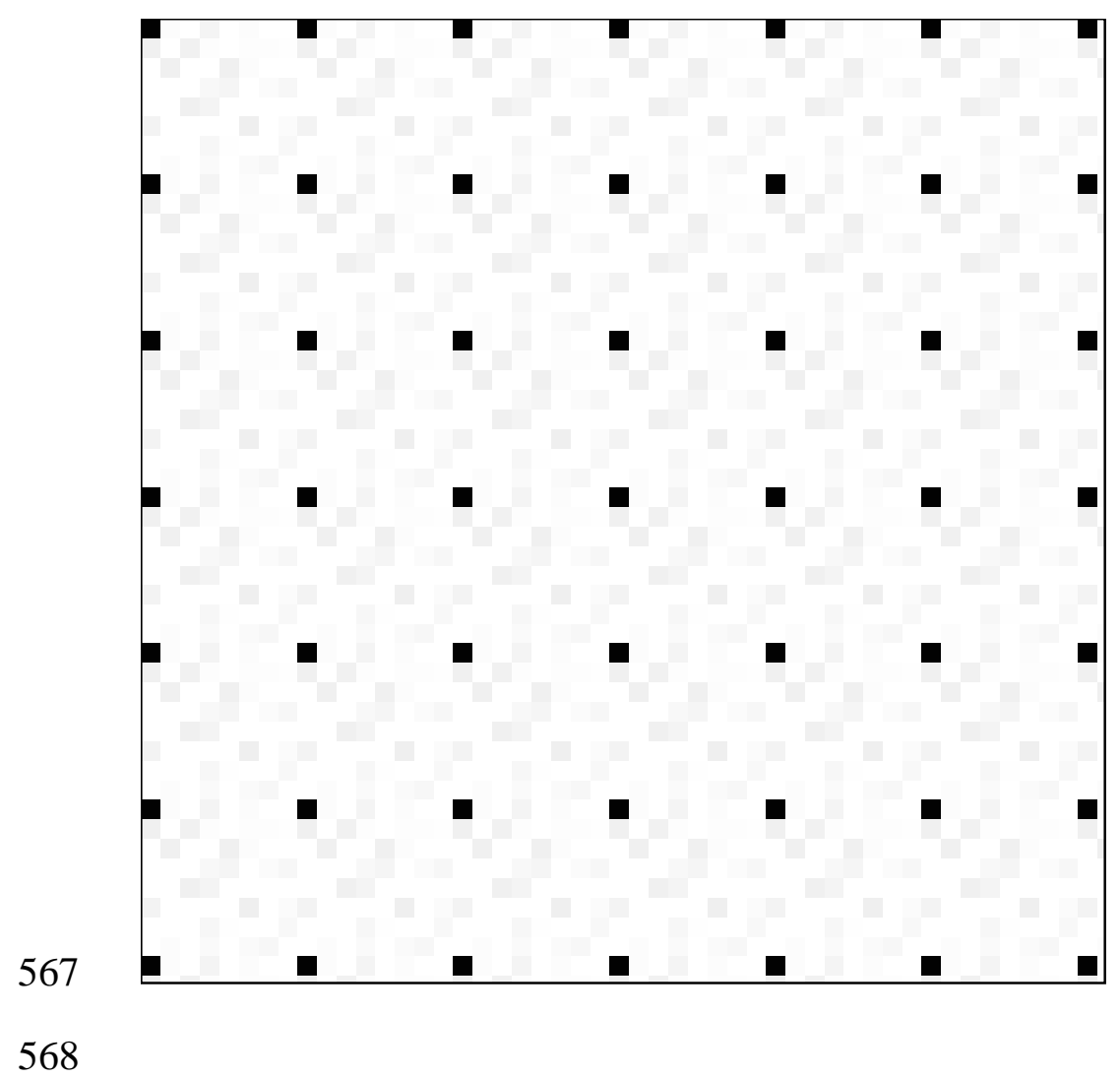


$569 \quad$ Figure 4.

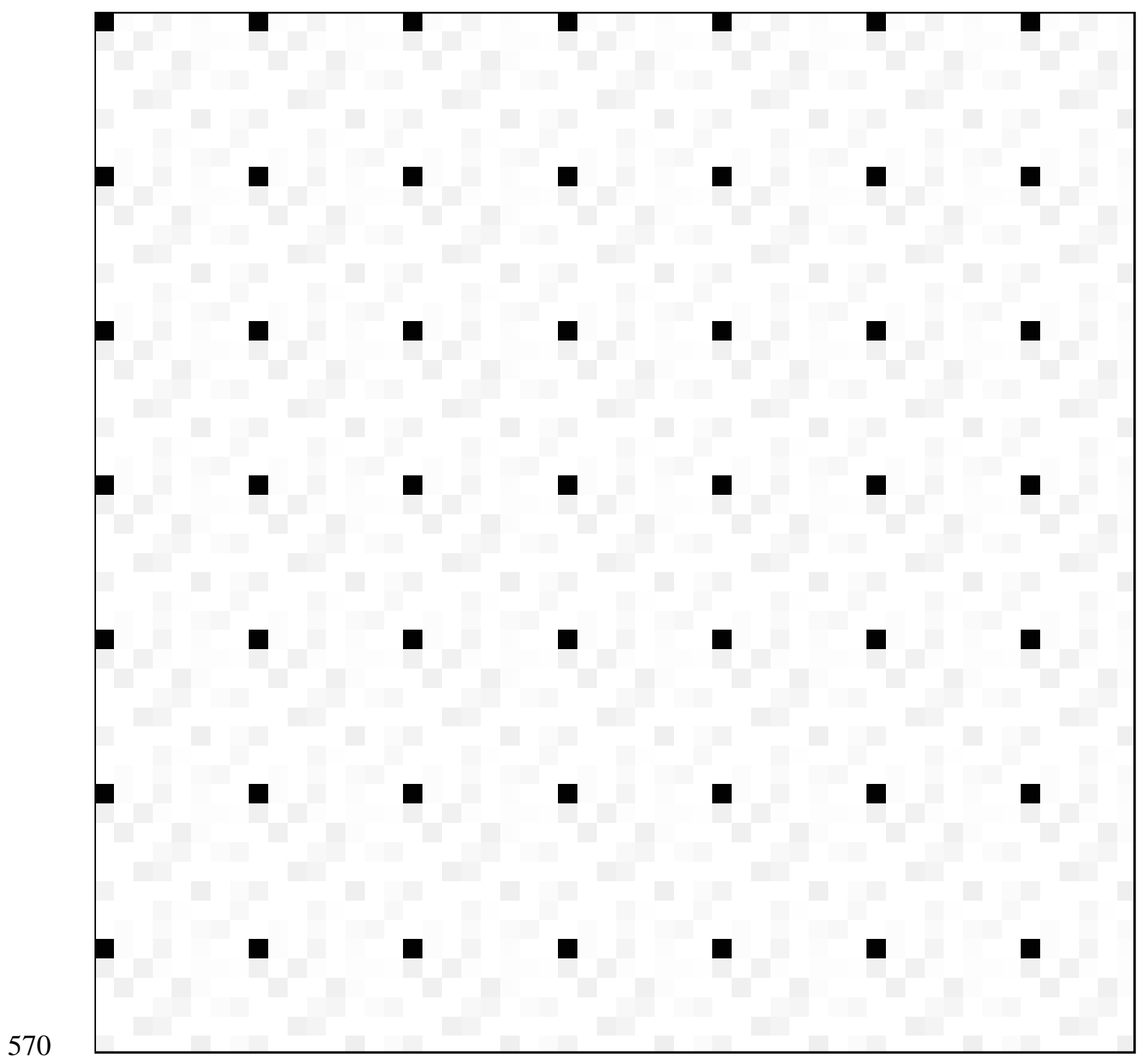

